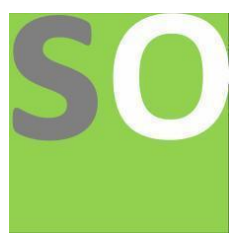

Article title: Emotional abuse forms, process, patterns and ways to overcome Authors: Bhanu Srivastav [1]

Affiliations: India[1]

Orcid ids: $0000-0002-4023-8473[1]$

Contact e-mail: fiwape8614@goqoez.com

License information: This work has been published open access under Creative Commons Attribution License http://creativecommons.org/licenses/by/4.0/, which permits unrestricted use, distribution, and reproduction in any medium, provided the original work is properly cited. Conditions, terms of use and publishing policy can be found at https://www.scienceopen.com/.

Preprint statement: This article is a preprint and has not been peer-reviewed, under consideration and submitted to ScienceOpen Preprints for open peer review.

DOI: 10.14293/S2199-1006.1.SOR-.PPOZ81O.v1

Preprint first posted online: 10 May 2021

Keywords: Emotional abuse, Domestic abuse 
EMOTIONAL ABUSE

Forms, Process, Patterns and Ways to overcome

\section{BHANU SRIVASTAV}

(This research is done for the Novel - Deified The Legacy of Yesterday) 
Discussion report

2|P a g e 


\section{Highlights}

- Emotional abuse is a technique used to exert power over another person by criticizing, humiliating, blaming, or otherwise manipulating them with their emotions.

- Emotional violence is one of the most difficult types of abuse to identify.

- Emotional abuse is often overlooked as abuse by survivors of domestic violence.

- Emotional abuse has a variety of effects on the victim.

- 65 percent of Indian men, women should accept abuse in order to hold the family together.

- Domestic abuse affects $70 \%$ of women in India (Physical, Sexual, Emotional \& Economic).

- Different forms of emotional abuses in India are:

a. Accusation of her character or behavior, etc.

b. Harassment for failing to carry dowry, etc.

c. Discrimination for not having a boy child

d. Discrimination for not having a child

e. Dissuading the wife from getting a job

- Individuals who are emotionally abusive have inflated expectations.

- Individuals that are emotionally abusive invalidate you.

- Individuals that are emotionally abusive cause havoc.

- Individuals who are emotionally abusive use emotional.

- Individuals who are emotionally abusive seem superior and entitled.

- Individuals that are emotionally abusive tend to isolate and manipulate you

- You must prioritize your mental and physical health.

- Define Boundaries and inform the abusive person that they are no longer permitted to scream at you, call you names, threaten you, or be disrespectful to you.

- Put an End to Your Self-Blame.

- Recognize That You Cannot Fix Them.

- Avoid Involvement

- Avoid interacting with an abusive individual.

- Discuss your feelings with a trusted friend, family member, or even a psychologist. 


\section{Introduction}

Emotional abuse (or psychological abuse) is a pattern of conduct that threatens, frightens, stigmatizes, or subtly underminesa person's self-worth. Psychological abuse, according to the Istanbul Convention, is "the deliberate act of seriously impairing a person's psychological integrity by intimidation or threats. "Emotional abuse may take the form of minimizing, threats, isolation, public embarrassment, and un-relenting criticism, relentless devaluation of self, coercive control, persistent stonewalling, and gas-lighting. Victims often believe their partner has near-total influence over them, which significantly alters the power dynamic in a relationship, enabling the suspect while disempowering the survivor. Victims also suffer from depression, which puts them at an elevated risk of developing eating disorders, suicide, and substance abuse. Long-term emotional violence has a crippling impact on the sense of self and dignity of the victim. Oftentimes, research indicates that emotional abuse is a precursor to physical abuse when three specific types of emotional abuse are present in the relationship: threats, restraint of the abused group, and property harm.

Psychological abuse is often overlooked as abuse by survivors of domestic violence. According to Goldsmith and Freyd's analysis of college students, many individuals who have endured emotional violence do not perceive the mistreatment as abusive. Additionally, Goldsmith and Freyd demonstrate that these individuals display a higher incidence of al exithymia than the general population (difficulty identifying and processing their own emotions) (Goldsmith \& Freyd, 2005). This is also the case when discussing abuse victims in relationships, as failure to recognize the behavior as abusive can be a coping or defensive mechanism used to master, mitigate, or accept stress or conflict.

According to English et al., children whose families experience interpersonal abuse, including psychological and verbal aggression, can display a variety of serious disorders, including chronic depression, anxiety, post-traumatic stress disorder, dissociation, and rage. Furthermore, English et al. report that the effect of emotional abuse "was not substantially different" from that of physical abuse (DJ et al., 2009).

Glaser explains that violence has a variety of effects on the child, most notably on their actions, including "insecurity, low self-esteem, disruptive behavior, inadequate development of fundamental skills, alcohol or substance abuse, suicide, trouble forming relationships, and dysfunctional work histories." 
- According to India's National Crime Records Bureau, recorded cases of crime against women rose by $6.4 \%$ in 2012 , and a woman is victimized every three minutes. According to the National Crime Records Bureau, there were over 228,650 registered cases of crime against women in 2011, but over 300,000 in 2015 , a 44 percent rise.

- Andhra Pradesh is home to 7.3 percent of India's female population and 11.5 percent of all women-related crimes registered.

- According to 65 percent of Indian men, women should accept abuse in order to hold the family together, and women sometimes deserve to be battered.

- Domestic abuse affects $70 \%$ of women in India (Physical, Sexual, Emotional \& Economic).

Exact data on case occurrences are extremely difficult to obtain, since a significant number of cases go unreported. This is largely due to the fear of mockery or embarrassment on the part of the prospective reporter, as well as intense pressure not to jeopardize the family's honor. 


\section{Different forms of emotional abuses in India}

\section{a. Accusation of her character or behavior, etc.}

It is now well established that if any imputations against the character of any spouse are made without any basis and are based on mere suspicion, such baseless allegations of illicit relationship amount to mental abuse, and it would be a valid ground for treating his act as sexual abuse under this Act or for passing a divorce decree unjustly (Chang, 1996).

\section{b. Harassment for failing to carry dowry, etc.}

Where the husband and his mother demanded dowry money and the wife twice paid the money. The wife was beaten mercilessly and thrown out of the marital home. Even after her frequent insults, the wife expressed her readiness and willingness to rejoin her husband, but the husband refused to accept her back. As a result, the husband tried to exploit his own mistake by insulting her for not bringing the dowry. In a Delhi case, the husband and his family members had decided on dowry, but their greed continued eventwo years after the marriage, and the wife was treated shabbily by them, with various demands for extra dowry: When their demands were not met, the husband and his family members turned to filing a petition to get rid of her and pursue dowry elsewhere. The husband was sim ply using his own wrongdoings and was not entitled to any compensation. In one case, it was decided that the husband should not be permitted to profit from his mistake, and that he never tried to accommodate the wife's fair desires, which is also a require ment for the marriage's stability.

\section{c. Discrimination for not having a boy child}

Where the husband claimed that it was the plaintiff wife who insisted on his taking a second woman because she had given birth to a daughter and believed that, for one thing, she would never be able to give birth to sons and that her husband should have boy-children, which is only possible by another woman. The claim seemed to be absurd, so the trial court ruled that it could not be believed. The Court should not place undue em phasis on a son's spiritual need for a Hindu who can provide a funeral cake and liberation for his ancestors. The respondent will adopt a son if it is absolutely appropriate.

\section{d. Discrimination for not having a child}

Where the husband constantly mocked the wife for not being able to give birth to a child by another woman. It's conceivable that the husband isn't medically capable of bearing the child. The husband's story should not be believed by the court. The Court should not place undue emphasis on a Hind u's need for a son for spiritual reasons. The respondent will adopt a son if it is absolutely appropriate. 


\section{e. Dissuading the wife from getting a job}

Preventing the wife from taking up her job at the workplace is incompatible with a woman's integrity and honor and must be abolished. It is a type of sex discrimination that may be perpetrated by the husband on the grounds that she is subjected to unwanted sexual advances, demands for sexual favors, or otherverbal or physical behavior, the rejection or submission of which may have an adverse impact on her job or work performance, or would create an unpleasant or hostile work atmosphere for her. Such events, in reality, infringe on her constitutional rights to gender equality, as well as her right to life and liberty. India was a signatory to a number of international treaties on the subject. The Beijing Declaration on Women and the 1979 Convention on the Elimination of All Forms of Discrimination against Women direct all State Parties to take effective steps to protect women's honor and dignity, as well as the International Covenant on Economic, Social, and Cultural Rights. The Supreme Court stated that courts have an obligation to ensure that the foreign instruments' messages are not drowned out, particularly when there is no inconsistency between them and a gap in domestic law (Stephenson, Wickham, \& Capezza, 2018). 


\section{Cycle of emotional abuse.}

Verbal and emotional violence, like other forms of abuse, occurs in a cyclical pattern.

\section{Step 1: Tension-Building:}

Daily life stresses such as conflict over children, marital affairs or sexual tension, misunderstandings between spouses, or other family disagreements lead to sickness, legal or financial issues, unemployment, or tragic incidents such as rape. The abuser feels neglected, threatened, irritated, upset, or unable to act as the alpha during this time of lockout, and in an effort to relieve the pressure and retain control, the abuser is provoked and has the urge to rape.

\section{Abusive Behavior:}

The attacker retaliates with offensive, demeaning, or hurtful language. The violence is usually a power play to remind the victim "who is in charge."

\section{culpability:}

The offender may feel guilty after abusing, but not for their behavior. The abuser becomes more concerned about being caught and facing repercussions for his or her behavior.

\section{Explanations:}

In the fear of losing the victim, the abuser rationalizes what he or she has done, making a series of excuses or blaming the victim for the abusive behavior, or something else to avoid taking responsibility.

\section{Typical behavior:}

The abuser does everything he can to reclaim ownership of the relationship and hold the survivor in it. To avoid losing the victim, the abuser may behave as if nothing happened, or he or she may resort to charm. This is known as the honeymoon period, and its aim is to give the survivor hope that the abuser has changed for the better this time.

\section{Fantasy and preparation:}

The abuser begins to fantasize about assaulting the victim again, and therefore spends a significant amount of time looking for gaps in the victim's job so that the abuser may make the victim pay, as well as plotting a strategy for making the abuser's fantasy of violence a fact. 


\section{Preparation:}

The preceding process is simply a means for the abuser to justify his or her actions in abusing the victim. 


\section{How Is Emotional Abuse Defined?}

Emotional abuse is a technique used to exert power over another person by criticizing, hu miliating, blaming, or otherwise manipulating them with their emotions. In general, a relationship is considered emotionally abusive when a pattern of abusive language and bullying actions wears down a person's self-esteem and jeopardizes their mental health. Additionally, while mental or emotional abuse is most prevalent in dating and married relationships, it can occur in any relationship, including those between friends, relatives, and coworkers (Capezza, D'Intino, Flynn, \& Arriaga, 2021).

Emotional violence is one of the most difficult types of abuse to identify. It can be covert and deceptive or overt and manipulative. In any case, it erodes the victim's self-esteem and causes them to question their perceptions and facts. The ultimate purpose of emotional violence is to exert power over the victim by discrediting, isolating, and silencing him or her. Finally, the survivor feels imprisoned. They are frequently too injured to continue in the relationship but often too terrified to leave. Thus, the loop continues indefinitely until something is finished. 


\section{How Are You Certain?}

Bear in mind when contemplating your own relationship that emotional violence is often subtle. As a consequence, it can be extremely difficult to identify. If you're having difficulty determining if your relationship is abusive, take a step back and consider how your experiences with your girlfriend, mate, or family member make you feel. The following are indicators that you might be involved in an emotionally abusive relationship. Bear in mind that even though your partner engages in just a few of these behaviors, you remain in an emotionally abusive relationship.

Avoid the temptation to rationalize their actions by telling yourself "it's not that bad." Bear in mind that everyone needs to be treated with dignity and kindness. If you often experience feelings of being hurt, irritated, confused, misunderstood, depressed, nervous, or useless in your interactions, the likelihood is that your relationship is emotionally abusive (Longares, Rodríguez-Carballeira, Escartín, \& Garrido-Rosales, 2019).

\section{Possess Irrational Expectations}

Individuals who are emotionally abusive have inflated expectations. Several examples include the following:

- Imposing unfair requirements on you

- Expecting you to set all other considerations aside in order to satisfy their needs

- Requiring that you spend your whole time together

- Constant dissatisfaction regardless of how hard you try or how much you offer

- Condemning you for failing to complete assignments in accordance with their expectations

- Expecting you to express their viewpoints (i.e., you are not permitted to have a different opin ion)

- Insisting on specific dates and times while addressing issues that vex you (and when you cannot do this, they may dismiss the event as if it never happened) 
Individuals that are emotionally abusive invalidate you. Several example s include the following:

- Subverting, denying, or distorting your perceptions or truth

- Refusing to acknowledge your emotions by attempting to describe how you should feel

- Constantly requiring you to justify how you feel

- Assaulting you with being "excessively sensitive," "excessively emotional," or "crazy"

- Refusing to recognize or consider the validity of your views or ideas

- Dismissing your requests, desires, and needs as absurd or unjustifiable

- Suggestions that your assumptions are incorrect or that you are untrustworthy by using phrases such as "you're exaggerating" or "you exaggerate"

- Accusing you of being self-centered, materialistic, or needy if you share your desires or needs (the expectation is that you should not have any wants or needs)

\section{Create Disarray}

Individuals that are emotionally abusive cause havoc. Several examples include the following:

- Initiating claims solely for the sake of argumentation

- Rendering ambiguous and incoherent claims (sometimes called "crazy-making")

- Substantial mood swings or unexpected emotional outbursts

- Picking at your clothing, hair, and job, among other things 
- Behaving in such an unpredictable and chaotic manner that you feel as if you're "walking on eggshells"

\section{Use of Emotional Blackmail}

Individuals who are emotionally abusive use emotional blackmail. Several examples include the following:

- Manipulating and controlling you by instilling guilt in you

- Making you feel humiliated in public or in private

- Attempting to exert control over you or the situation by appealing to your fears, beliefs, sympathy, or other emotional triggers

- Exaggerating or highlighting the shortcomings in order to divert focus or avoid accepting responsibility for their bad decisions or errors

- Refusing to acknowledge the occurrence of an incident or fabricating information about it

- Punishing you by denying love or by treating you silently

\section{Act Superior}

Individuals who are emotionally abusive seem superior and entitled. Several examples include the following:

- Behaving as though you are inferior

- Holding you accountable for their errors and shortcomings

- Casting doubt on everything you say and trying to disprove you 
- Making jokes about you

- Asserting that your beliefs, concepts, principles, and feel ings are foolish, illogical, or "make no sense"

- Addressing you in a patronizing manner or being condescending

- Engaging with you with sarcasm

- Pretending to always be right, to know what is best, and to be smarter than others

Take Control and Isolate you

Individuals that are emotionally abusive tend to isolate and manipulate you. Several examples include the following:

- Having the ability to choose who you see and spend time with, including friends and family

- Surveillance of your digital communications, including text messages, social media, and email

- Accusing you of infidelity and being envious of your external relationships

- Stealing or concealing the automobile keys

- Insisting on knowing where you are at all times or tracking your every move through GPS

- Treating you as though you were a possession or a piece of property

- Making fun of or criticizing your peers, relatives, and coworkers

- Using envy and jealousy as a means of expressing love and preventing you from being with others 
- Conspiring to compel you to spend all of your time together

- Financial management

The Different Types of Emotional Abuse

Emotional abuse can manifest itself in a variety of ways, including the following:

- Accusations of infidelity or other manifestations of envy and possessiveness

- Constant monitoring or other attempts to exert control over the actions of another person

- Constant argumentation or opposition

- Condemnation

- Deception

- Isolating the subject from family and friends

- Insults and verbal bullying

- Refusal to be a part of the partnership

- Condemning or blaming

- Care in a discreet manner

- Making the other person's worries insignificant

- Refusing to give affection and consideration 
It is important to keep in mind that these forms of violence may not be obvious at the start of a relationship. While a relationship may appear to be natural and caring at first, abusers may begin using strategies to dominate and exploit their partner as the relationship progresses. These behaviors may begin so slowly that you may not recognize them at first. 


\section{Impact of Emotional Abuse's}

When emotional violence is serious and persistent, a person can lose all sense of self, often without leaving a single mark or bruise. Other than that, the wounds are invisible to others, concealed behind the victim's self-doubt, worthlessness, and self-loathing. Indeed, evidence suggests that mental abuse has almost as serious effects as physical abuse.

Accusations, physical bullying, name-calling, criticisms, and gaslighting gradually erode a victim's sense of self to the point that they can no longer view themselves objectively. As a result, the victim may begin to concur with the abuser and develop an internal critic. Once this occurs, the majority of victims become stuck in the abusive relationship, convinced that they will never be good enoughfor another.

Emotional abuse may also have an effect on friendships, as emotionally exploited individuals often worry about how others really see them and whether they truly like them.

Victims eventually withdraw from friendships and isolate themselves, believing that no one cares for them. Additionally, emotional violence can result in a variety of health issues, including depression and anxiety, as well as stomach ulcers, heart palpitations, eating disorders, and insomnia. 


\section{Suggestions for Overcoming Emotional Abuse}

Recognize the violence as the first step toward resolving an emotionally abusive relationship. It is important to consider every form of emotional violence in your relationship first and foremost. By being candid about your feelings, you will reclaim control of your life. Here are seven additional techniques for reclaiming your life that you can immediately implement.

\section{Make Self-Care a Priority}

You must prioritize your mental and physical health. Put an end to your concern about appeasing the individual who is abusing you. Take care of your own requirements. Make a decision that will assist you in thinking positively and affirming who you are.

Additionally, ensure that you get enough rest and consume nutritious foods. These straightforward self-care measures will go a long way toward assisting you in coping with the daily pressures of emotional violence.

\section{Define Boundaries}

Inform the abusive person that they are no longer permitted to scream at you, call you names, threaten you, or be disrespectful to you. Then inform them of the consequences of engaging in this action. For example, inform them that if they use derogatory language or disrespect you, the conversation will end and you will exit the room. The trick is to adhere to your limits.

\section{Put an End to Your Self-Blame}

If you have been in an emotionally abusive relationship for an extended period of time, you may feel that you have a serious mental illness. However, you are not the problem. Abuse is an option. Therefore, refrain from punishing yourself for anything over which you have no power.

\section{Recognize That You Cannot Fix Them}

Regardless of how hard you try, you will never be able to influence an emotionally abusive person by doing or being anything different. An abusive individual chooses to act abusively. Remind yourself that you have no power over their behavior and are not responsible for their decisions. The onl y aspect of your situation that you can alter or influence is your answer. 


\section{Avoid Involvement}

Avoid interacting with an abusive individual. In other words, if an abuser attempts to start an argument with you, starts bullying you, makes demands of you, or rages with envy, do not attempt to justify yourself, soothe their feelings, or make apologies for things you did not do. Simply exit the situation if possible. By engaging with an abuser, you open yourself up to more violence and heartache. You will never be able to make it right in their minds, regardless of how hard you try.

\section{Establish a Support System}

Although it can be difficult to communicate what you are going through, speaking up can be beneficial. Discuss your feelings with a trusted friend, family member, or even a psychologist. Spend as much time as possible away from the abusive person and with others who love and help you. This network of healthy friends and confidantes will assist you infeeling less alone and lonely. Additionally, they will speak reality into your life and assist you in putting events into perspective. 


\section{References}

« Capezza, N. M., D'Intino, L. A., Flynn, M. A., \& Arriaga, X. B. (2021). Perceptions of Psychological Abuse: The Role of Perpetrator Gender, Victim's Response, and Sexism. Journal of Interpersonal Violence. https://doi.org/10.1177/0886260517741215

$\aleph \quad$ Chang, V. N. (1996). I just lost myself: Psychological abuse of women in marriage. Greenwood Publishing Group.

§ DJ, E., JC, G., RR, N., TL, L., R, T., JB, K., \& C, W. (2009). At-risk and maltreated childrenexposed to intimate partner aggression/violence: what the conflict looks like and its relationship to child outcomes. Child Maltreatment.

« Goldsmith, R. E., \& Freyd, J. J. (2005). Awareness for emotional abuse. Journal of Emotional Abuse. https://doi.org/10.1300/J135v05n01 04

ふ Longares, L., Rodríguez-Carballeira, Á., Escartín, J., \& Garrido-Rosales, S. (2019). A qualitative study of psychological abuse in same-gender couples: Identification, types, and explanations. Psykhe. https://doi.org/10.7764/psykhe.28.2.1479

§ Stephenson, V. L., Wickham, B. M., \& Capezza, N. M. (2018). Psychological Abuse in the Context of Social Media. Violence and Gender. https://doi.org/10.1089/vio.2017.0061 